\title{
Literatura y nihilismo en la obra de Jean Paul
}

\author{
Literature and nihilism in Jean Paul's Works
}

Gonzalo Portales

Universidad Austral de Chile, Instituto de Filosofía y Estudios Educacionales,

Valdivia, Chile.e-mail: gportale@uach.cl

A la memoria de Hans-Jürgen Gawoll.

En el contexto de la discusión sobre el nihilismo, acontecida en la filosofía alemana de inicios del siglo XIX se desarrolla una fuerte polémica en la que también se ve comprometida la creación literaria. Este artículo presenta algunos aspectos fundamentales de la obra poética de Jean Paul y su relación con esta controversia, exponiendo la diferencia de sus intentos teóricos con aquellos provenientes de la ficción, especialmente de la fantasía onírica.

Palabras clave: filosofía, literatura, nihilismo.

In the context of the discussion on nihilism in German philosophy in the early XIX century, a strong controversy is developed in which literary creativeness is involved. This paper presents some important aspects of Jean Paul's poetic production and its relationship with this controversy, explaining the difference of its theoretical intentions with those coming from fiction, especially those related to oniric fantasy.

Key words: philosophy, literatura, nihilism.

Aun cuando en la historia del pensamiento occidental se ha impuesto el tópico que identifica el momento decisivo de la disputa sobre el nihilismo con el contenido de la obra fragmentaria e inédita de Friedrich Nietzsche, planificada largamente y realizada en forma parcial durante las últimas décadas del siglo XIX, no siempre se advierte, sin embargo, que esos textos de la filosofía del nihilismo europeo expresan, en realidad, más bien el desenlace de una polémica iniciada casi cien años antes en un ámbito en que la discusión no se reducía sólo a una cuestión filosófica sobre el nihil, pues sus premisas pertenecían también a una controversia proveniente de la literatura y del pensamiento poético de los inicios del así llamado Romanticismo alemán.

Durante la célebre disputa sobre el panteísmo que acabó con el forzado alejamiento de Fichte de la Universidad de Jena en los últimos años del siglo XVIII, conocida con el nombre de Pantheismusstreit (Cf. Röhr 1991 y Jacobs 1984), Friedrich Heinrich Jacobi introdujo en lengua alemana la expresión Nihilismus para referirse a toda perspectiva derivada del monismo substancialista de Spinoza y del racionalismo ilustrado de Lessing. Su crítica posición había sido dada a conocer al público no sólo mediante su memorable discusión filosófica con Mendelssohn (Über die Lehre des Spinoza in Briefen an den Herrn Moses Mendelssohn, 1785), sino que había encontrado también una expresión estética a través de sus novelas Allwil (1781-1826) y Wodemar (1779-1826). Esta "doble" participación en la polémica tuvo como efecto que las tesis de Jacobi fueran fecundamente recepcionadas en los círculos literarios de la época (Cf. Jaeschke 2004) ${ }^{1}$. Entre los escritores fue, sin duda, Jean Paul quien con más entusiasmo celebró estas agudas críticas a la "filosofía nihilista", participando directamente en la polémica mediante su escrito satírico Clavis fichteana, publicado el año 1800 luego de haber sido revisado por el propio Jacobi ${ }^{2}$.

\footnotetext{
${ }^{1}$ Con ocasión de la publicación de la Wissenschaftslehre de 1794, escribe Goethe el 23 de mayo del mismo año una carta a Jacobi en la que se burla del concepto de Nicht-Ich; el poeta Clemens Brentano compuso su parodia sobre el filisteo expresamente para mofarse de Fichte. Distinto es el modo de la recepción de Hölderlin, quien en un conservador esbozo sobre la obra de Jacobi (Zu Jacobis Briefen über die Lehre des Spinoza, escrito entre 1790-1791), muestra un nítido interés por la discusión. Hegel, por su parte, manifestó en su juventud, tal como lo atestiguan sus cartas, haber seguido en detalle la discusión de finales de siglo, y dirigió, en sus últimos años, su ironía contra Jacobi, de quien afirma en su escrito berlinés sobre la obra de Hamman -en el Jahrbücher für wissenschftliche Kritik de 1828-, que "redactaba cartas porque no era capaz de escribir un libro". Por último, mencionemos también que el joven Fr. Schlegel escribió una precisa reseña de la novela Woldemar en la revista Deutschland el año 1796.

${ }^{2}$ El título alude a la obra Clavis Ciceroniana de Johann August Ernesti. La referencia a este trabajo de uno de los fundadores de la
} 
En términos teóricos, adoptar las posturas de Jacobi contra la filosofía trascendental y el idealismo significa también no otorgar ningún alcance a la negatividad, o dicho con más exactitud, a la función de la negación en el proceso del movimiento dialéctico, instante éste que expresaría, justamente, el momento protagónico del nihil en el acontecimiento de lo que es o de lo que deviene ser. Así sucede, por ejemplo, en el concepto fichteano de $\mathrm{No}$-Yo en tanto momento negativo de la reflexión o en la Nada pura del comienzo de la Ciencia de la lógica de Hegel, que en su pretendida absolutez e indeterminación se muestra equivalente al Ser puro.

Pero bajo esta polémica que bien podría parecer "técnica" -si se la entendiese como la cuestión del significado de la negatividad y el nihil- se encuentra un conflicto oculto totalmente determinado por una discrepancia religiosa, el que bien puede ser interpretado como uno de los últimos resabios ilustrados en los inicios del romanticismo alemán. La tercera de las tesis que Jacobi expone en su discusión con Lessing dice escuetamente: Spinozismus ist Atheismus. A juicio de estos críticos es totalmente inherente a la nueva subjetividad fundada en la actividad autopoiética la negación de cualquier fundamento o ultima ratio en que pudiese sustentarse no sólo la existencia humana, sino la totalidad de los entes. Se trataría de una orfandad ontológica que simultáneamente tendría el sentido de un fracaso de la razón, evidenciándose su incapacidad para arribar argumentativamente a un principio explicativo que no necesitase a su vez de una explicación ulterior. El carácter religioso de la discusión vuelve a situar el problema en la contraposición entre creatio y anihilatio, otorgándole al acto poiético de la divinidad la única garantía posible contra la amenaza del nihil. ${ }^{3}$

También la correspondencia entre Jean Paul y Jacobi (cf Röhr, 1991, 443-444) confirma la posición compartida entre el filósofo y el poeta en relación a la discusión teórico-religiosa sobre el nihilismo, manifestando incluso su complicidad -aunque no desprovista de cierta compasión- con respecto al certero ataque que finalizaría con la carrera académica de Fichte en la Universidad de Jena. Sin embargo, se produce una sugestiva fisura entre lo que podríamos llamar la opinión pública de Jean Paul expresada sin ambigüedad en los textos recién señalados- y su convicción poética con respecto a los contenidos de la misma disputa. Por esto, es posible sostener que bajo la ingeniosa argumentación satírica de las páginas de la Clavis Fichtiana se disimula una genuina inquietud por las consecuencias de la teoría de la subjetividad expuesta por la filosofía idealista, aflicción que habría provocado en Jean Paul una actitud ambivalente que lo habría forzado a oscilar entre la admiración (Bewunderung) y el rechazo (Ablehnung) de la doctrina del Yo (Ich-Lehre) desarrollada por Fichte. (Jean Paul III, 1130).

El fundamento de esta doble perspectiva se encuentra, a mi juicio, en el hecho de que la concepción estética de Jean Paul dista mucho de su "opinión” filosófico-religiosa, pudiendo así admitir para el ámbito de la poíesis lo denegado para el espacio propio de la ciencia. De esta manera, si bien al comienzo de su Estética $(\mathrm{V}, 30-34)^{5}$ parece prolongar aún la discusión teórica, en la medida en que se esfuerza por denunciar al Nihilismo poético (der poetische Nihilismus) en tanto "arbitrariedad de la egomanía" (Willkür der lchsucht), basta avanzar sólo algunos parágrafos para advertir que lo que allí se investiga constituye un objeto muy distinto de aquel que componía al Pantheismusstreit. La sintonía de este programa sobre el arte con otros acontecimientos contemporáneos se percibe, sobre todo, en la apropiación que él realiza tanto de la nomenclatura poética de Schiller como del lenguaje de los manifiestos estéticos de los jóvenes de la Escuela de Jena, principalmente de los hermanos Schlegel, pero también de los ensayos sobre la fantasía (Phantasien über die Kunst) de Wackenroder y Ludwig Tieck: "Si se aplica lo romántico (das Romantische) a las formas poéticas (Dichtungarten)" -escribe en el § 25-, "lo lírico se transforma en sentimental, lo épico en fantástico, como el cuento, el sueño, la novela; el drama se transforma en ambos, pues él es propiamente la unificación de ambas formas poéticas" $(\mathrm{V}, 101)^{6}$.

hermenéutica moderna contiene, evidentemente, un juego humorístico, pues equipara su escrito satírico con un texto fundado en la "seriedad" y "gravedad" del método interpretativo, el que Ernesti entiende como una construcción científica.

${ }^{3}$ Esta cuestión específica y sus raíces escolásticas las he tratado anteriormente en mi trabajo Nihil y Poiésis. La controversia sobre el nihilismo y la escuela romántic, en revista Etcetera (2000).

${ }^{4}$ La expresión proviene de una nota crítica del editor Norbert Miller. "Schon seit längerer Zei hatte sich Jean Paul eingehend, zwischen Bewunderung und Ablehnung schwankend, mit Fichtes Ich-Lehre beschäftigt'. Cf. también v. Borries (1997, 325).

${ }^{5}$ El texto se titula Vorschule der Ästhetik y fue publicado en 1804. La historia de su producción comienza, sin embargo, en el año 1794, con la redacción de las Äthetische Untersuchungen, prolongándose en 1803 con el texto Programme úber die Kunst, que sirvió de base para una serie de Lecciones en la Universidad de Leipzig. (Cf. V, 1197 y ss.).

${ }^{6}$ Cf. también el ensayo estético Über die natürliche Magie der Einbildungskraft en IV. 195-205. 
Lo que aquí se intenta proteger del poder de "aniquilación del idealismo de la filosofía" es, precisamente, la validez de lo onírico para la producción artística. Jean Paul ha sido caracterizado con razón como "el maestro indiscutible del sueño" o "el poeta del gran sueño cósmico [...] donde el yo se pierde voluptuosamente en espacios infinitos" (Béguin 1994: 212). Su principal aporte a la modernidad literaria del Romanticismo estaría dado por esta esforzada lucha contra el reduccionismo egomaníaco y sus secuelas antropocéntricas - presente ya en el giro subjetivo de la meditatio cartesiana y su sospecha vigilante y culminando en la tautologia scientiae del $Y_{O}=Y_{O}$ de Fichte-, oponiéndole el poivhma de las infinitas posibilidades de ser, cuyo acceso privilegiado lo constituiría la experiencia onírica.

La fidelidad a tal apertura hacia lo infinitamente posible posee también efectos sobre la propia creación literaria, en la que se producen derivaciones que en ocasiones podrían irritar al lector habituado al relato omnisciente, pues la trama de sus novelas y cuentos se ve, al parecer, demasiadas veces interrumpida por la interposición de sueños que harían perder el hilo conductor de la acción dramática. Béguin (213) habla a este respecto de "intermedios autónomos" que bien podrían llevar a formular el juicio de que en el caso de Jean Paul se trataría de un "inhábil narrador, siempre seducido por el paréntesis lírico y cómico". Prefiero pensar, sin embargo, que dicho procedimiento se inscribe en la intencional utilización estilística -común a varios de los autores del primer Romanticismo- de la ironía literaria, la cual, como había insistido Friedrich Schlegel, suele terminar por ser aplicada a la obra propia $^{8}$. Tal cuestión ha sido y permanecerá controvertible, pues se constata que lo mismo que para algunos se presenta como mera confusión propia de cierta ineptitud escritural, es considerado por otros como el resultado de un estricto trabajo integrador de una diversidad de formas de habla y de voces disímiles que parecen componer una polifonía literaria de refinado humor. Desde esta segunda perspectiva se observa una complejidad experimental de los textos jean-paulinos que le imprimen un sello indiscutible de pertenencia a la literatura moderna (Cf. Esselborn: 1992: 32 y ss.).

A diferencia del Idealismo filosófico, cuyo pensamiento no progresa sino via negationis, esto es, no pasa a otro estadio hasta haber vencido la contradicción mediante el movimiento de la superación o Aufhebung, los románticos sí pueden cohabitar con ella desde el momento en que la operatividad irónica no se confronta con aquello que se le opone, sino que permite un desarrollo paralelo que atenúa la regula autoritaria de la lógica ${ }^{9}$, posibilitando al menos de esta manera que los contrarios puedan subsistir en sus sentidos fragmentarios y ensimismados y que compongan ellos mismos a su vez, no obstante, un mundo (un kovsmo") capaz de tolerarlos en su diferencia. Quizás sea éste el motivo por el que se muestra admisible la permanencia de la contradicción entre la obra poética de Jean Paul, en la que pueden tener cabida incluso el delirio, el horror y lo siniestro (das Unheimliche) y su posición teórica frente a la disputa sobre el nihilismo, caracterizada por una racionalidad que recurre a la prescripción taxonómica de la realitas instaurada a partir de una jerarquía de fines y medios, es decir, que se impone mediante la fuerza de un orden sustentado en una teleología axiomática.

Hablar (en este caso, escribir) desde el sueño otorga cierta inmunidad obsequiada por el hecho de que "después de todo nada era cierto", de que no existe la intención de declarar real lo acontecido en dicha experiencia y de que por lo tanto no se es responsable de sus consecuencias. Así se pueden describir sin ataduras ontológicas ni éticas hechos que en otro contexto serían considerados censurables, pues el lector ya está advertido del carácter puramente ficticio del relato. Pero, por otra parte, desde la antigüedad se ha vinculado también la vivencia onírica con lo visionario -en griego o[neiro" se relaciona habitualmente con o[yi" y en latín existe una comunidad de sentido entre somnium y visio-, de tal manera que muchas veces el contenido de los sueños posee un significado que enseña y profetiza, mostrándose aún más efectivo en lograr impresiones que modifiquen la conducta que el discurso de las disciplinas psicológicas o de la prédica moral (Cf. Schmidt-Hannisa 2001: 94 y ss.).

Un análisis descriptivo de aquellos sueños que se interceptan como "intermedios autónomos" al contenido dramático de la obra en prosa de Jean Paul, nos puede mostrar ciertos arquetipos literarios en

\footnotetext{
${ }^{7}$ Cf. V, 401: "Der vernichtende Idealismus der Philosophie, der das unwillkürliche Wachen und das unwillkürliche Träumen in einen höhern wechsellosen willkürlichen Traum auflöset, erinnert an Moritz' Bemerkung, daß Träume, die sich nicht verdunkeln, sondern sich hell ins Wachen mengen, leicht allmählich aus der Schlafkammer in eine dunklere geleiten".

${ }^{8}$ No puedo detenerme en este contexto en la relación entre ironía y humor en el romanticismo, refiero para ello al polémico trabajo de Ingrid Strohschneider-Kohrs (2002, 147 y ss.). Sí parece relevante insistir, sin embargo, en el hecho de que la ironía literaria es un producto común de los autores románticos, la cual viene a superar la estrecha concepción de una ironía retórica, cuya definición se había mantenido prácticamente inalterada desde la Intitutio oratoria de Quintiliano ("In utroque enim contrarium ei quod dicitur intelligendum") hasta la Encyclopédie.
}

9 Me refiero aquí a la Logik en sentido hegeliano y no a la lógica instrumental del Organon aristotélico. 
los que se manifiesta el modo en que se desarrolla el universo poético de su creador y su ambigüedad frente a la dicotomía planteada. En primer lugar, me referiré al sueño del personaje Walt, contenido en las últimas páginas del extenso texto biográfico titulado Flegeljahre (II, $1061 \mathrm{y}$ ss.) ${ }^{10}$. Se trata de un auténtico viaje cósmico-temporal hacia los orígenes, hacia el Ur-Sprung o salto primigenio identificado con el comienzo en cuanto tal, origen que no está exento de alusiones a la ajrchv vetero y neotestamentaria con su creatio ex nihilo y logos inicial, pero más evidente aún, según mi opinión, a la arcaica cosmogonía contenida en los comienzos de la Teogonía de Hesíodo, esa que comienza en el caos (Kavo") y culmina con la obra de [Ero", "el más bello (kavllisto") entre los dioses inmortales"11. El caos tiene aquí el sentido propio de una catástrofe universal en la que todo forcejea por llegar a ser, en la que el mundo invisible (die unsichtbare Welt) deja que nazcan de manera desordenada y confusa flores, rostros, estrellas y tormentas, sin que ellas configuren aún un equilibrio formal. El momento caótico de

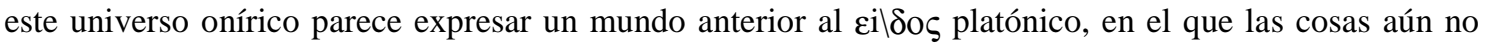
han encontrado su lugar y apenas sí han comenzado a ser nombradas (es wurde mir im Traum alles genannt). En páginas anteriores del mismo relato, Jean Paul había acuñado la enigmática expresión "Lust-Chaos" (II, 629), la que tal vez -sostengo provisoriamente- quiera señalar el hecho de que esta confusa acción creadora sea al mismo tiempo un acontecimiento placentero y que, por esto mismo, haya sido conservado de algún modo misterioso en la memoria humana, poseyendo entonces este "Sueño del Universo" (Béguin, 217) el significado de un puente fantástico que nos une con lo arcaico "como si la imaginación tendiera un lazo inexplicable entre nosotros y las épocas más remotas del globo".(id.). La vorágine de los nacimientos del sueño de Walt, cuyo fin y reposo se alcanza mediante una suave luz matinal (Morgenlicht) en el horizonte -que, dicho sea de paso, me parece una bellísima figura que coincide con el despertar, con el abandono del sueño-, encuentra un principio formal, o si se quiere, un orden eidético, en la acción de Eros. Es por medio del deseo propio de la fiesta orgiástica que las creaturas son "liberadas" del caos tenebroso, rescatadas del movimiento vertiginoso de lo ominoso o unheimlich, puestas a salvo de aquello que siempre se presenta como la extrema alteridad, como el momento más cercano a la nada. Pero la tranquilidad del triunfo de Eros es nuevamente interrumpida por la advertencia de que dentro de la extrema experiencia onírica su acto es asimismo también un sueño (die Liebe träumt).

Entre los escasos escritos de Jean Paul traducidos al castellano se encuentra otro relato de viaje cósmico que ha sido editado bajo el título de Sueño del Universo (Cf. Marí 1998: 45-47). En esta ocasión no se trata de un retorno al origen (Ursprung), sino de un vuelo astral por el universo actual, de una migración celestial posibilitada por un desdoblamiento identitario que se desprende de la constitución corpórea. Si se tuviese que elegir una expresión que diese cuenta íntegramente del contenido de esta breve narración, creo que lo más adecuado sería hablar del sentimiento de angustia (Angst) provocado por la absoluta inconmensurabilidad de la infinitud espacial. Parece casi inevitable aludir en este contexto al pathos pascaliano de la sensación de abismo insalvable que impera entre la condición ontológica del anthropos y la incalculable extensión del espacio. ${ }^{12}$ Escasas veces se menciona que la historia de la modernidad y sus auténticos progresos ha heredado también representaciones aporéticas que llegan a conducir al desquicio de la imaginación (Einbildungskraft). Uno de estos problemáticos legados ha sido, ciertamente, la configuración postcopernicana del orbe y su radical inversión del punto de vista del observador. El efecto inmediato de este giro óptico parece excesivo no sólo a causa del arduo trabajo de duelo demandado por la pérdida de centralidad planetaria y del evidente menoscabo de los tradicionales privilegios antropológicos, sino además porque desde ese mismo cambio revolucionario procede una nueva topografía cósmica que prescinde de límites reconocibles y con ello queda impedida de guardar alguna proporción analógica con las facultades imaginativas de la representación.

Este parece ser el estado de animo onírico que se produce cuando a la pregunta: “¿acaso no tiene fin (Ende) el universo?", formulada por el soñador del relato -demasiado agobiado ya por el viaje a través

\footnotetext{
10 Literalmente el título equivale a nuestra expresión coloquial edad del pavo.

11 Hesíodo, Teogonía 116 y ss: "En primer lugar existió el Caos. Después Gea la de amplio pecho, sede siempre segura de todos los inmortales que habitan la nevada cumbre del Olimpo (...) Por último Eros, el más hermoso entre los dioses inmortales..." h[toi me;n prwvtista Cavo gevnetV: aujta;r e[peita Gai`æ eujruvsterno , pavntwn e\{doj ajsfale aijei; ajqanavtwn oi[ e\{cousi kavrh nipovento" jOluvmpou,(...), hjdæ' "Ero", o\{ kavllisto" ejn ajqanavtoisi qeoi`si...

12 "Porque, al fin, ¿qué es el hombre en la naturaleza? Una nada frente al infinito [...] Infinitamente alejado de comprender los extremos, el fin de las cosas y su principio (la fin des choses et leur principe) están para él invenciblemente ocultos en un secreto impenetrable (dans un secret impénétrable)" (Pascal 1936: 50). Jean Paul no sólo ha sido lector de los fragmentos de Pascal, sino que los ha integrado productivamente a su obra, como se evidencia por las referencias contenidas en los trabajos Leben des Quintus Fixlein, Siebenkäs y Vorschule der Ästhetik.
} 
de la inmensidad de los espacios, en los que se ha llegado a tocar la desolación del cielo vacío-, se responde: "no tiene principio (Anfang)". En este preciso instante el personaje experimenta un estremecimiento contrario al pavor frente a la falta de medida del infinito, pues constata aterrado que si "el universo es finito", entonces nos encontraríamos en la "interminable cárcel nocturna de la creación" (Cf. Morí: 45-46), en el encierro asfixiante de límites que impiden pensar un más allá (Jenseits) hacia el cual se pudiese avanzar hacia una salida. Cualquiera de las dos alternativas -finitud e infinitud-conduce ineludiblemente al horror vacui. La expresión resume la sentencia escolástica natura abhorret vacuum y que viene a sintetizar una larga tradición -en torno al concepto griego to; keno;n, el vacíoproveniente de la física antigua y que en los comienzos de la modernidad, por ejemplo en Bacon, será equiparada con la nada: vacuum nihil est et nulla natura. El espacio puro sin ningún contenido corpóreo es inadmisible para la imaginación humana, y su carácter ominoso (unheimlich) provoca necesariamente el estado horroroso de la presencia del nihil, esto es, de la presencia de aquello que no es sino ausencia. El horror queda constituido, pues, por una imposibilidad, por una monstruosidad, expresándose como la tenebrosa aparición de aquello que de suyo no puede ser visible. ${ }^{13}$ Cuando el sueño padece esta experiencia que repugna totalmente a la vigilia, se vuelve insoportable y es abruptamente interrumpido por el despertar que -como es habitual en cada uno de los relatos analizados- reconcilia al hombre (Mensch) con el mundo y con su destino ${ }^{14}$.

En la novela Hesperus ${ }^{15}$, el estado hipnótico transporta al personaje Emanuel a una circunstancia que lo lleva a ser testigo de un acontecimiento desconcertante. Momentos antes de quedarse dormido, Emanuel y Julius habían estado platicando sobre la muerte, o mejor dicho, sobre el morirse, haciendo alusión a la posibilidad de que si uno tocaba en la flauta la canción del encantamiento (Lied der Entzückung), el otro podía morirse en los tonos (an den Tönen sterbe(n)), lo que equivale a decir que podía dejar de existir desvaneciéndose en la música, lo cual les parece un muy buen ejemplo de aquello que habitualmente se denomina una muerte dulce. Motivado por esta conversación, Emanuel sueña que "un gozo aniquila a todas las almas". ${ }^{16}$ Esta inquietante experiencia de carácter apocalíptico sucede a través de un ángel exterminador (Engel des Endes) que encanta a las almas para que éstas se desvanezcan dulcemente en la luz (am Lichte), en el aroma (am Duft) o en los sonidos (an Tönen), culminando su acción con un gran abrazo devastador que acaba con todo el género humano (das Ganze Menschengeschlecht), el que, por su parte, se aproxima gozoso a su destrucción (I, 1148). ${ }^{17}$ Y luego de esta total extinción del hombre, la acción exterminadora continúa anulando toda restualidad que pudiese insinuar aún la mera posibilidad del ser: el mismo ángel, consternado esta vez hasta las lágrimas, disuelve también en la nada al tiempo (Zeit, cro;no").

El sentido estricto de este sueño permanece, a mi juicio, indescifrable. En él no ocurre simplemente la muerte que tiene como sujeto al cuerpo (sw`ma) -factum admitido sin reservas por la tradición filosófico-teológica occidental-, sino que lo que allí acontece es una definitiva supresión del alma (yuchj), imagen ésta ya extraña a Occidente, pues con ella se prescinde del más preciado de los legados platónicos vigentes en el cristianismo: la inmortalidad del alma ${ }^{18}$. Una aproximación indirecta a esta misteriosa renuncia podría autorizar a afirmar que tal vez se trate de un intento por presentar esta consumada aniquilación (Vernichtung) al modo de una ajpokatavstasi", es decir, de exponerla bajo la forma de aquel movimiento hacia el nihil que la teología alejandrina había concebido como una "vuelta de todas las creaturas al estado anterior al de la creación", como un retorno a la nada desde la cual la creación misma se había iniciado en tanto creatio ex nihilo. La vivencia onírica de Emanuel parece querer señalar así que un catastrófico momento común de placer sublime posee más valor que una perpetuidad regulada por la mera duración mecánica de la temporalidad, esto es, por crovno", quien -

\footnotetext{
13 Otras veces se trata de imposibilidades sensibles que, sin embargo, no provocan angustia, sino más bien una cierta diversión lúdica, como cuando en sueño se oyen los colores o se ve una melodía musical.

${ }^{14}$ Así, por ejemplo, el párrafo final de Sueño del Universo: "Pero el júbilo siguió en mí tras mi despertar y dije: ‘¡Oh, qué
hermoso es morir en la creación, tan llena, tan luminosa, y qué hermoso es vivir en ella!'. Y di gracias al creador por la vida en esta tierra, y por la futura de la que no estaremos privados.

15 Hesperus fue la novela más exitosa de las escritas por Jean Paul, habiendo alcanzado rápidamente las tres ediciones, la primera en 1795 , la segunda tres años más tarde en 1798 y la última en 1819.

${ }^{16}$ El título en alemán reza: “Traum Emanuels, daß alle Seelen eine Wonne vernichte” (Cf. I, 1145 y ss.).

17 "Und der Engel des Endes öffnete die Arme weit und drückte das ganze Menschengeschlecht in eine Umarmung zusammen”.

18 Me refiero principalmente a la doctrina que una larga tradición ha creado a partir de Fedón 64c y ss., en que la muerte es considerada "la separación del alma del cuerpo" (...th`" yuch`" ajpoj tou` swvmato ajpallaghvn).
} 
como se sabe- siempre termina por devorar a sus propios hijos.

No sólo el lector queda abrumado por la enorme desolación que provoca este sueño. El autor también manifiesta el padecimiento de sus secuelas y busca por ello mitigar en parte sus insoportables consecuencias. El capítulo final de Hesperus relata el momento exacto en el que anteriormente se había realizado la escritura del sueño de Emanuel, confesando ahora el poeta que en ese instante se encontraba bajo los efectos de "una dulce escalofriante embriaguez"19. Esta confidencia tiene, en el contexto de la obra jean-paulina, el significado de una disminución irónica del aterrador contenido del sueño de la aniquilación (Traum der Vernichtung), ya que en otra parte (Cf. Siebenkäs, II, 415) se proclama que es posible igualar al dormido con el demente y el ebrio (Schlafende, Wahnsinnige und Trunkene). La turbadora visión de Emanuel y la escritura del poeta son de esta manera suavizados por Jean Paul y retornan desde la extrañeza radical -desde lo Unheimliche - hacia los muy familiares efectos del desvarío de la locura y del delirium de la embriaguez. La arraigada vigilia vuelve a proscribir a los demonios oníricos y restaura con perseverancia el mundo habitual de las cosas y de los hombres.

Quisiera finalizar estas tentativas reflexiones sobre nihilismo y literatura examinando algunos aspectos del sueño más célebre y controvertido de los escritos por Jean Paul. Me refiero al titulado El discurso del Cristo muerto, contenido en el segundo volumen de Siebenkäs (II, 266-271). El relato en primera persona comienza informando al lector que el sueño ha ocurrido en una noche veraniega cuando el personaje se ha dormido a la intemperie en una montaña. La primera sorpresa es que se trata esta vez de un sueño dentro de un sueño, pues lo que se sueña es que se ha despertado por causa del ruido producido por las ruedas giratorias del reloj de una torre al marcar las once de la noche. El segundo asombro es que esta vigilia onírica lo ha trasladado al fin de los tiempos, justo en el instante en que sucede la resurrección de los muertos profetizada en los Evangelios ${ }^{20}$, y que él advierte en un alucinante derredor en el que "todas las tumbas estaban destapadas" ${ }^{21}$. El entorno es el comienzo amenazador conforme a la tradición literaria apocalíptica-, se cruzan en él inquietantes sombras (Schatten), de los cielos baja una niebla gris y bochornosa (ein grauer schwüler Nebel) y se escucha el sacudimiento de un terremoto inconmensurable (Tritt eines unermeßlichen Erdbebens); pero al acercarse al sitio donde se encontraba emplazada la iglesia del lugar, aparece la noble figura (edle Gestalt) de Cristo. El tercer desconcierto es que a pesar de que su presencia revelaba a la muchedumbre el cumplimiento de la promesa escatológica y la resurrección (ajnavstasi") le confirmaba la culminación de la historia soteriológica (swthriva), el semblante de Cristo no coincidía con tal momento de júbilo, sino que, por el contrario, su rostro denotaba el padecimiento de un "dolor perpetuo" (ein unvergänglicher Schmerz).

Entonces, la multitud recientemente resucitada, que ya presentía los motivos de su interminable sufrimiento, exclamó en voz coral la terrible interrogación: “¡Cristo! ¿No hay ningún Dios? (ist kein Gott?)”. Y él contestó: "¡No hay ninguno!" (Es ist keiner!). El intenso silencio en que quedaron inmersos aquellos hombres que aún no terminaban de despojarse de sus indumentarias mortuorias, permitió luego que se oyera nítidamente el testimonio de la insoportable angustia que afligía a Cristo: "He recorrido los mundos, he cabalgado los soles y he volado con las vías lácteas por los desiertos del cielo; pero no existe Dios alguno. He bajado incluso allí donde el ser proyecta sus sombras y he mirado en el abismo y he llamado 'Padre ¿dónde estás?', pero no he oído más que la eterna tormenta que nadie gobierna, y el destellante arcoiris de los seres se alzaba sobre el abismo sin un sol que lo creara, y se diluía gota a gota. Y, cuando mi mirada se alzó hacia el mundo infinito en busca del ojo divino, el mundo me miró fijamente con una órbita vacía y rota; y la eternidad yacía en el caos y lo roía y se masticaba a sí misma" (II, 269) 22 .

A mi juicio este párrafo es la imagen más directa de lo que podríamos denominar nihilismo

19 “...wo ich Emanuels Traum von der Vernichtung mit süßer schauernder Trunkenheit schrieb” (I, 1232). Corresponde también a un gesto paradigmático de la ironía literaria el hecho de que el autor se introduzca a sí mismo en la narración ficticia.

${ }^{20}$ Por ejemplo, en el Evangelio de Juan 5, 28-29: "No os asombréis de esto, porque llegará la hora cuando todos los que están en los sepulcros oirán su voz; y los que hicieron lo bueno saldrán a resurrección de vida; pero los que hicieron lo malo, a resurrección de

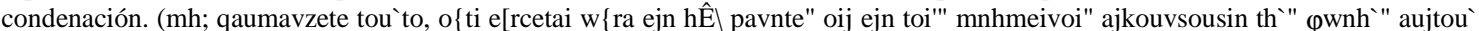
kai; ejkporeuvsontai, oiJ tajgaqa; poihvsante" eij" ajnavstasin zwh`", oiJ de; ta; $\varphi$ au`la pravxante" eij" ajnavstasin krivsew".”).

21 “Alle Gräber waren aufgetan" (II, 268).

22 "Ich ging durch die Welten, ich stieg in die Sonnen und flog mit den Milchstraßen durch die Wüsten des Himmels; aber es ist kein Gott. Ich stieg herab, soweit das Sein seine Schatten wirft, und schauete in den Abgrund und rief: 'Vater, wo bist du?' aber ich hörte nur den ewigen Sturm, den niemand regiert, und der schimmernde Regenbogen aus Wesen stand ohne eine Sonne, die ihn schuf, über dem Abgrunde und tropfte hinunter. Und als ich aufblickte zur unermeßlichen Welt nach dem göttlichen Auge, starrte sie mich mit einer leeren bodenlosen Augenhöhle an; und die Ewigkeit lag auf dem Chaos und zernagte es und wiederkäuete sich". 
teológico o para usar una feliz expresión heideggeriana, ontoteológico. El modo radical en que la divinidad es causa en la tradición teológica tiene como consecuencia el hecho de que advertir su inexistencia significa simultáneamente privar de fundamento a todo aquello cuyo ser se entiende como efecto de esa causa, de tal manera que este sueño expresa la total anihilatio, el paso del ser a la nada. Unas líneas más adelante, la falta-de-fundamento ${ }^{23}$ anunciada por el discurso de Cristo alcanza también al hombre y su patética miseria marcada por la orfandad: "¡Qué solo está cada uno en la inmensa tumba del universo! A mi lado no estoy más que yo. ¡Oh, padre! ¡Oh padre! ¿Dónde está tu seno infinito para que yo pueda descansar sobre él? Ay, si cada Yo es su propio padre y creador, ¿por qué no puede ser también su propio ángel exterminador?... ¿Sigue siendo un hombre el que está a mi lado? ¡Infeliz! Su breve vida es un suspiro de la naturaleza..." 24.

El relato del Discurso del Cristo muerto prolonga el suspenso de manera proporcional a la monumentalidad de su destrucción, haciendo que el personaje despierte justo en el preciso instante cuando "estaba a punto de dar la última hora del tiempo (die letzte Stunde der Zeit) y destruir el edificio del mundo (Weltgebäude)". El final acude a un conocido esquema de inversión y se siente el gran alivio de comprobar que todo no había sido más que un sueño. El despertar llena al personaje de alegría y lo confirma en su fe y devoción.

Este recuperado sosiego de la vigilia no impide, sin embargo, el inquietante recuerdo de haber experimentado un lúcido delirio onírico en el que el destino del cristianismo -en su afán de querer ir al encuentro del padre (pathvr) - parece limitar su eficacia a una patriarcal voz humana que tal vez aún podría otorgar sentido a la existencia del animal que tiene logos (zw'Êon logon e[con), pero que se encontraría imposibilitado de siquiera vislumbrar algún sentido que pudiese "yacer" más allá de las estrellas (meta;-sideral), en donde la conditio de la paternitas ya no posee el significado de causa, pues el acontecimiento del nacer (gevnesi") describiría exclusivamente a ese modo del llegar a ser que deviene bajo la forma de la existencia. La vasta terra incognita fuerza a reconocer que "in principio [non] erat Verbum” (ejn ajrch 'Ê a oujk ${ }^{\circ} \mathrm{h} \mid \mathrm{n}$ oj Lovgo"), sino quizás más bien el inmemorial Kavo cosmogónico de nuestro viejo y aún siempre evocado Hesíodo. Con ello Jean Paul ha abierto definitivamente las puertas a la polémica sobre el nihilismo que atravesará todo el siglo XIX en la filosofía y la literatura alemana.

\section{OBRAS CITADAS}

Fuente principal:

Jean Paul. 1960-1963. Werke. Edición de Norbert Miller. 6 tomos. Manchen: Hanser Verlag.

\section{Literatura:}

Béguin, Albert. 1994. El alma romántica y el sueño. Ensayo sobre el romanticismo alemán y la poesía francesa. México: Fondo de Cultura Económica.

Esselborn, Hans. 1992. "Die Vielfalt der Redeweisen und Stimmen. Jean Pauls erzählerische Modernität". En: Jahrbuch der Jean-Paul-Gesellschaft. n 26/27, p. 32-66.

Jaeschke, Walter (ed.). 2004. Friedrich Heinrich Jacobi: ein Wendepunkt der geistigen Bildung der Zeit. Hamburg: Felix Meiner Verlag.

Jacobs, Wilhelm. Johann Gottlieb Fichte. Hamburg: Rowohlt.

Marí, Antoni. 1998. El entusiasmo y la quietud. Antología del romanticismo alemán. Barcelona: Tusquets.

Ortheil, Hanns-Josef. 1996. Jean Paul. Hamburg: Rowohlt.

Pascal. 1936. Pensées. París: Le livre de poche.

Röhr, Werner (ed.). 1991. Appellation an das Publikum... Dokumente zum Atheismusstreit. Jena 1798/99. Leipzig: Reclam.

Schmidt-Hannisa, Hans Walter. 2001. "Der Traum ist unwillkUrliche Dichtkunst. Traumtheorie und

\footnotetext{
${ }^{23}$ Llamo la atención sobre esta expresión que en alemán se dice Abgrund, palabra que significa también abismo y que pertenece al grupo de los términos más usados en la literatura jean-paulina.

${ }^{24}$ Wie "Wie ist jeder so allein in der weiten Leichengruft des Alles! Ich bin nur neben mir - O Vater! o Vater! wo ist deine unendliche Brust, daß ich an ihr ruhe? - Ach wenn jedes Ich sein eigner Vater und Schöpfer ist, warum kann es nicht auch sein eigner Würgengel sein?... Ist das neben mir noch ein Mensch? Du Armer! Euer kleines Leben ist der Seufzer der Natur...”.
} 
Traumaufzeichnung bei Jean Paul”. En: Jahrbuch der Jean-Paul-Gesellschaft 35/36: 93-113.

Schulz, Gerhard. 1989. Die deutsche Literatur zwischen Französischer Revolution und Restauration. München: C.H. Beck.

Strohschneider-Kohrs, Ingrid. 2002. Die romantische Ironie in Theorie und Gestaltung. Tübingen: Max Niemeyer Verlag.

Von Borries, Erika u. Ernst. 1997. Deutsche Literaturgeschichte (t. 4. Zwischen Klassik und Romantik. Hölderlin, Kleist, Jean Paul). München: DTV. 